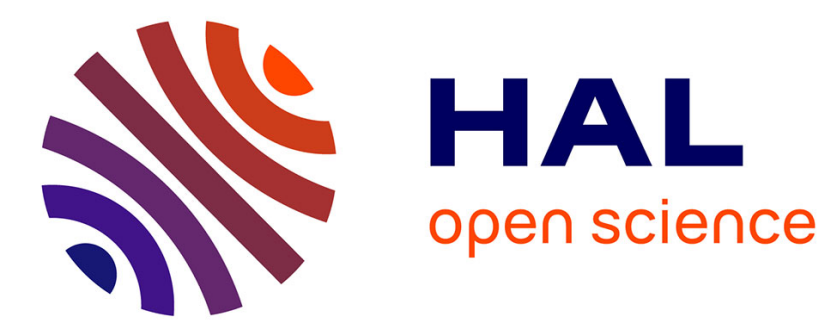

\title{
Phase-Separation, Partitioning and Precipitation in MA956, an ODS Ferritic Stainless Steel
}

\author{
H. Read, K. Hono
}

\section{To cite this version:}

H. Read, K. Hono. Phase-Separation, Partitioning and Precipitation in MA956, an ODS Ferritic Stainless Steel. Journal de Physique IV Proceedings, 1996, 06 (C5), pp.C5-223-C5-228. 10.1051/jp4:1996536 . jpa-00254415

\section{HAL Id: jpa-00254415 https://hal.science/jpa-00254415}

Submitted on 1 Jan 1996

HAL is a multi-disciplinary open access archive for the deposit and dissemination of scientific research documents, whether they are published or not. The documents may come from teaching and research institutions in France or abroad, or from public or private research centers.
L'archive ouverte pluridisciplinaire HAL, est destinée au dépôt et à la diffusion de documents scientifiques de niveau recherche, publiés ou non, émanant des établissements d'enseignement et de recherche français ou étrangers, des laboratoires publics ou privés. 


\title{
Phase-Separation, Partitioning and Precipitation in MA956, an ODS Ferritic Stainless Steel
}

\author{
H.G. Read and K. Hono \\ National Research Institute for Metals, 1-2-1 Sengen, Tsukuba 305, Japan
}

\begin{abstract}
The behaviours of as-received and recrystallised (homogenised) MA 956, an Al-containing Cr-rich ferritic stainless steel, aged at $475{ }^{\circ} \mathrm{C}$ for up to 2900 hours have been investigated. Atom probe microanalysis of the decomposition products revealed that $\mathrm{Al}$ did not partition significantly to the Fe-rich phase after $\approx 600$ hours ageing, contrary to thermodynamic predictions. Ageing to 2900 hours, however, resulted in partitioning. Further thermodynamic analysis showed that the chemical potential of $\mathrm{Al}$ in the $\mathrm{Cr}$-rich $\alpha^{\prime}$ phase increased more rapidly at later stages of phase separation. The wavelength and amplitude of decomposition were found to be significantly larger in aged as-received material compared to aged homogenised material, consistent with coarsening accelerated by the enhanced solute mobilities associated with the highly-dislocated as-received material. Ti- and Si-rich precipitates were found at the $\alpha / \alpha^{*}$ interfaces at later stages of ageing.
\end{abstract}

\section{INTRODUCTION}

The hardening of binary $\mathrm{Fe}-\mathrm{Cr}$ alloys during ageing at low temperatures (so-called ' $475^{\circ} \mathrm{C}$ embrittlement') has been shown, by atom probe field ion microscopy (APFIM), to be due to the spinodal decomposition of the supersaturated solid solution into Fe-rich $\alpha$ and $\mathrm{Cr}$-rich $\alpha^{\prime}$ phases [1]. Additionally, it has been shown that similar decomposition occurs in the $\mathrm{Cr}$-enriched ferritic phase of duplex stainless steels and in singlephase $\mathrm{Fe}-\mathrm{Cr}$ based ternary and higher order alloys [2-14]. The addition of alloying elements $(\mathrm{Co}, \mathrm{Ni}, \mathrm{Si}$, $\mathrm{Mo}$ ) to the binary $\mathrm{Fe}-\mathrm{Cr}$ system has been shown to affect the kinetics and products of the decomposition process [2-14]. These alloying elements themselves partition preferentially between the $\alpha$ and $\alpha^{\prime}$ phases, as the decomposition reaction proceeds. The driving force for their partitioning arises from the reduction in the free energy of the system. However, it has been shown recently [15] that $\mathrm{Al}$ does not appear to partition preferentially to the Fe-rich $\alpha$ phase, as predicted thermodynamically, during ageing of up to $\approx 600$ hours at $475^{\circ} \mathrm{C}$ of MA 956, an Al-containing Cr-rich oxide-dispersion-strengthened (ODS) ferritic stainless steel produced by mechanical alloying. In the as-received state, the microstructure is characterised by all the features of cold-deformation: ultrafine (sub-micrometer) convoluted grains elongated in the working direction $(\approx 0.2 \times 4 \mu \mathrm{m})$ and a high dislocation density [16]. Subsequent heat-treatment of as-received material leads to primary recrystallisation, producing a very coarse-grained microstructure $(\approx 2 \times>40 \mathrm{~mm})$ similar to that of a directionally-recrystallised microstructure. The aims of this work were to investigate the partitioning behaviour of $\mathrm{Al}$ during phase separation of MA 956 when the $\alpha$ and $\alpha^{\prime}$ domains are expected to be in thermodynamic equilibrium and to investigate the effects of microstructure on the decomposition process. 


\section{EXPERIMENTAL}

The alloy, of nominal composition Fe-20Cr-4.5Al-0.5Ti-0.01C-0.5 $\mathrm{Y}_{2} \mathrm{O}_{3}$ (wt.\%) or Fe-20.2Cr-8.8Al$0.55 \mathrm{Ti}-0.044 \mathrm{C}$ (at.\%, ignoring $\mathrm{Y}_{2} \mathrm{O}_{3}$ addition), was supplied by INCO Alloys (Hereford, UK) in an unrecrystallised (as-received) state. It was fabricated by mechanical alloying of three primary powders (elemental iron, pre-alloyed metallic alloys and yttria) in a vertical water-cooled attritor. Consolidation of the resultant alloy powder was by canned extrusion at $1000^{\circ} \mathrm{C}$ and subsequent rolling.

Material for examination was machined from the core region of the as-received bar. Homogenisation treatment of 24 hours at $1300{ }^{\circ} \mathrm{C}$ resulted in full recrystallisation. Subsequent isothermal ageing at $475{ }^{\circ} \mathrm{C}$ was conducted for as-received and for homogenised material for times between 1 and 2900 hours. The final heat treatment was terminated by iced-water quench. Specimens for APFIM analysis were prepared by standard two-stage eletropolishing of blanks $(15 \times 0.23 \times 0.23 \mathrm{~mm})$ machined from the core of the bulk heat-treated specimens, parallel to the extrusion direction [15].

The atom probe characterisations were performed using a reflectron-based time-of-flight atom probe (Applied Microscopy Ltd. APFIM 220 [17]) equipped with a position-sensitive detector (PSD) (Kindbrisk Ltd. PDA60/L [18]) for position-sensitive atom probe (PoSAP) analysis. Atom probe analysis was conducted between temperatures of 50 and $80 \mathrm{~K}$, employing a pulse fraction of $20 \%$ at a pulse repetition rate of $200 \mathrm{~Hz}$. PoSAP analysis was conducted at $30 \mathrm{~K}$, at a pressure $\leq 7 \times 10^{-9} \mathrm{~Pa}$, at a pulse fraction of $15 \%$ and a pulse repetition rate of $200 \mathrm{~Hz}$. Hydrogen was not gated from detection so incorrect positioning of second ions was discarded. In the atom probe mass spectra, the peak at $m / n=25.0$ was assigned to ${ }^{50} \mathrm{Cr}^{2+}$ since the natural isotopic abundance of ${ }^{50} \mathrm{Ti}^{2+}$ is small $(5.34$ at.\%). The peak at $m / n=27.0$ was assigned to ${ }^{54} \mathrm{Fe}^{2+}$ since the natural isotopic abundance of ${ }^{54} \mathrm{Cr}^{2+}$ is small (2.38 at.\%) and $\mathrm{Al}$ was deemed to evaporate as ${ }^{27} \mathrm{Al}^{2+}$ and ${ }^{27} \mathrm{Al}^{3+}$ only. Silicon was deemed to evaporate as $\mathrm{Si}^{2+}$ only; hydrides of $\mathrm{Al}$ were ignored. All compositions quoted are in at.\%.

\section{RESULTS}

\subsection{Thermodynamic analysis}

Table 1 shows the compositions of the equilibrium Fe-rich and Cr-rich phases at $475{ }^{\circ} \mathrm{C}$, calculated employing the Fe and Scientific Group Thermodata Europe (SGTE) solution databases in ThermoCalc [19] and considering the equilibrium between $\alpha$ and $\alpha^{\prime}$ only. The miscibility gap in the Fe-Cr binary system was defined and employs the thermodynamic description due to Andersson and Sundman [20]. The solvus temperature for MA 956 is calculated as $764{ }^{\circ} \mathrm{C}$ and $548{ }^{\circ} \mathrm{C}$, employing the Fe and SGTE solution databases respectively. APFIM analysis of material aged at $560^{\circ} \mathrm{C}$ for $\approx 7200$ hours did not show evidence of phase separation (contrary to predictions employing the Fe database) and thus, the results calculated employing the SGTE solution database are potentially more reliable. It is seen that $\mathrm{Al}$ and $\mathrm{Ti}$ are predicted to partition strongly to the $\alpha$ phase.

Table 1: Calculated phase compositions at $475^{\circ} \mathrm{C}$. The mole fraction of the $\mathrm{Cr}$-rich phase is 0.17 and 0.11 , employing the $\mathrm{Fe}$ - and the SGTE solution databases respectively. $c_{A l}^{\alpha} / c_{A l}^{\alpha}$ is the ratio of the concentrations of $\mathrm{Al}$ in the $\alpha$ and $\alpha^{\prime}$ phases.

\begin{tabular}{|c|c|c|c|c|}
\cline { 2 - 5 } \multicolumn{1}{c|}{} & \multicolumn{2}{c|}{ Fe-database } & \multicolumn{2}{c|}{ SGTE solution database } \\
\cline { 2 - 5 } \multicolumn{1}{c|}{} & Fe-rich (at.\%) & Cr-rich (at.\%) & Fe-rich (at.\%) & Cr-rich (at.\%) \\
\hline $\mathrm{Fe}$ & 83.2 & 8.14 & 77.3 & 9.56 \\
$\mathrm{Cr}$ & 5.63 & 91.3 & 12.1 & 88.0 \\
$\mathrm{Al}$ & 10.5 & $5.9 \times 10^{-3}$ & 9.50 & 2.47 \\
$\mathrm{Ti}$ & 0.66 & $7.7 \times 10^{-3}$ & 0.61 & $3.34 \times 10^{-3}$ \\
$\mathrm{C}$ & $6.4 \times 10^{-4}$ & 0.51 & $4.85 \times 10^{-2}$ & $3.77 \times 10^{-3}$ \\
\hline \hline$c_{A l}^{\alpha} / c_{A 1}^{\alpha}$ & \multicolumn{2}{|c|}{1780} & \multicolumn{2}{c|}{3.85} \\
\hline
\end{tabular}




\subsection{APFIM analysis}

Composition depth profiles for aged recrystallised material are shown in Figure 1. The Cr composition depth profiles for aged materials clearly show the formation of the two-phase $\alpha+\alpha^{\prime}$ microstructure. Compositional analysis of the two phases formed on ageing both the recrystallised and the as-received material, as delineated from $\mathrm{Cr}$ ladder diagrams, is shown in Table 2. The mole fraction $V_{f}^{\alpha^{\prime}}$ of the $\mathrm{Cr}$-rich $\alpha^{\prime}$ phase was determined from the compositional data. Note that the overall $\mathrm{Cr}$ and $\mathrm{Al}$ contents differ slightly from the nominal for material aged $\mathbf{5 9 8}$ hours, possibly as a result of preferential evaporation effects at the compromised temperature of analysis.

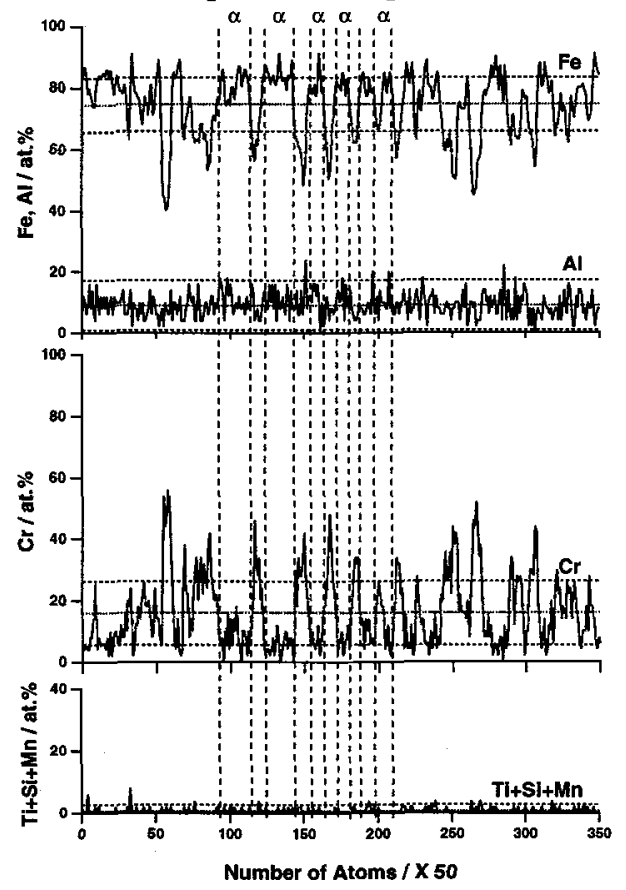

a)

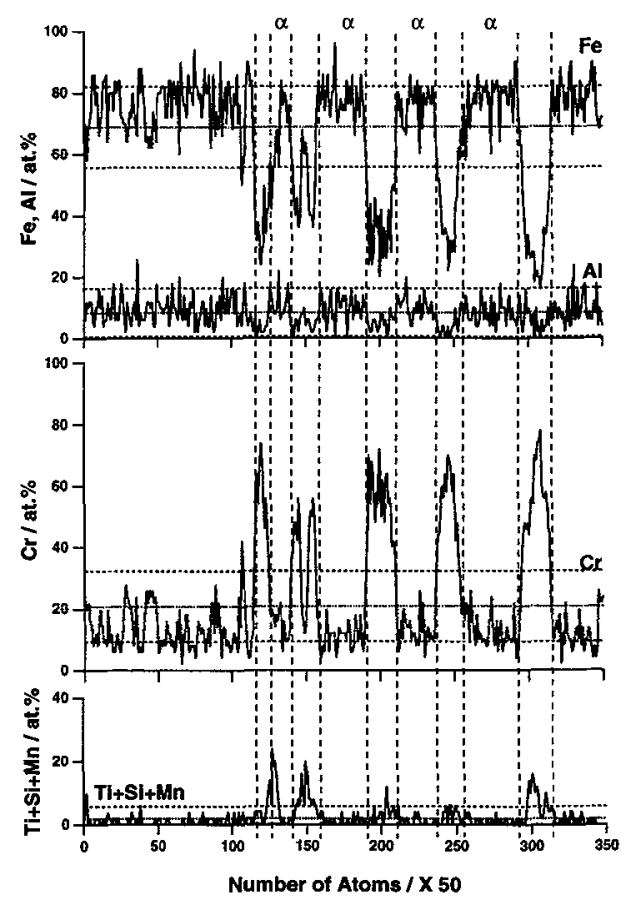

b)

Figure 1: Composition depth profiles for solute species in MA 956 . Block size is 50 ions. Depth of analysis $\approx 35 \mathrm{~nm}$. Horizontal dashed lines show the average solute contents and 95\% confidence intervals. (a) Recrystallised MA 956 aged at $475^{\circ} \mathrm{C}$ for 588 hours. The supersaturated solid solution has decomposed into Fe-rich $\alpha$ and Cr-rich $\alpha$ ' domains. The vertical dashed lines show some of the $\alpha / \alpha^{\prime}$ interfaces. (b) Recrystallised MA 956 aged at $475^{\circ} \mathrm{C}$ for 2900 hours. Both the wavelength $\lambda$ and the amplitude $\Delta c$ of decomposition have increased. Note Ti- and Si-rich phases near the $\alpha / \alpha$ ' interfaces.

Table 2: Measured phase compositions of aged MA 956. The mole fraction $V_{f}^{\alpha}$ of the Cr-rich phase is $\approx 0.6$ and $\approx 0.5$ after 588 hours and $\approx 0.2$ and $\approx 0.15$ after 2900 hours for the aged homogenised and aged recrystallised material respectively. $c_{A l}^{\alpha} / c_{A l}^{\alpha}$ is the ratio of the concentrations of $\mathrm{Al}$ in the $\alpha$ and $\alpha^{\prime}$ phases. All compositions are in at.\%.

\begin{tabular}{|c|c|c|c|c|c|c|c|c|}
\hline & \multicolumn{4}{|c|}{ Aged homogenised MA 956} & \multicolumn{4}{|c|}{ Aged as-received MA 956} \\
\hline & \multicolumn{2}{|c|}{588 hours @ $475^{\circ} \mathrm{C}$} & \multicolumn{2}{|c|}{2900 hours @ $475^{\circ} \mathrm{C}$} & \multicolumn{2}{|c|}{588 hours@ @ $475^{\circ} \mathrm{C}$} & \multicolumn{2}{|c|}{2900 hours@ @775 $\mathrm{C}$} \\
\hline & Fe-rich $\alpha$ & Cr-rich $\alpha^{\prime}$ & Fe-rich $\alpha$ & Cr-rich $\alpha^{\prime}$ & Fe-rich $\alpha$ & Cr-rich $\alpha^{\prime}$ & Fe-rich $\alpha$ & Cr-rich $\alpha^{\prime}$ \\
\hline $\mathrm{Fe}$ & $80.0 \pm 0.49$ & $61.3 \pm 0.78$ & $75.3 \pm 0.56$ & $38.3 \pm 0.76$ & $75.3 \pm 0.57$ & $52.7 \pm 0.67$ & $76.5 \pm 0.83$ & $27.9 \pm 0.98$ \\
\hline $\mathrm{Cr}$ & $8.0 \pm 0.34$ & $28.3 \pm 0.73$ & $13.1 \pm 0.43$ & $51.5 \pm 0.78$ & $8.6 \pm 0.37$ & $34.4 \pm 0.64$ & $12.4 \pm 0.65$ & $66.5 \pm 1.03$ \\
\hline $\mathrm{Al}$ & $10.7 \pm 0.38$ & $8.7 \pm 0.46$ & $9.50 \pm 0.38$ & $5.53 \pm 0.36$ & $15.6 \pm 0.48$ & $12.7 \pm 0.45$ & $10.5 \pm 0.60$ & $5.4 \pm 0.49$ \\
\hline $\mathrm{Ti}$ & $0.26 \pm 0.06$ & $0.21 \pm 0.07$ & $0.79 \pm 0.12$ & $0.63 \pm 0.12$ & $0.50 \pm 0.09$ & $0.25 \pm 0.09$ & $0.42 \pm 0.13$ & $0.09 \pm 0.07$ \\
\hline $\mathrm{Si}$ & $1.40 \pm 0.16$ & $1.71 \pm 0.24$ & $1.30 \pm 0.15$ & $4.08 \pm 0.31$ & & & & \\
\hline$\overline{c_{A l}^{\alpha} / c_{A l}^{\alpha}}$ & \multicolumn{2}{|c|}{$1.2 \pm 0.11$} & \multicolumn{2}{|c|}{$1.7 \pm 0.19$} & \multicolumn{2}{|c|}{$1.2 \pm 0.08$} & \multicolumn{2}{|c|}{$1.9 \pm 0.36$} \\
\hline
\end{tabular}


The amplitude $\Delta c$ of decomposition was determined by both the $P_{a}$ method [21] and by squarewave modelling of the measured composition profile [22]. The wavelength $\lambda$ of decomposition was determined from the autocorrelation function [21]. An estimate of the depth analysed was made using a method described previously [23]. Ageing recrystallised MA 956 to 2900 hours leads to a coarser scale of decomposition $(\lambda \approx 5 \mathrm{~nm})$ as compared to recrystallised material aged to 598 hours $(\lambda \approx 1.3 \mathrm{~nm})$. Additionally, the amplitude of the Cr composition fluctuations increases with time ( $\Delta c \approx 0.25$ and 0.24 after 598 hours, increasing to $\Delta c \approx 0.47$ and 0.40 after 2900 hours, employing the $P_{a}$ and square wave models respectively), consistent with spinodal decomposition. Ageing as-received MA 956 to 2900 hours leads to a coarser scale of decomposition ( $\lambda \approx 8 \mathrm{~nm}$ c.f. $\lambda \approx 5 \mathrm{~nm}$ after 598 hours ageing). The amplitude of the $\mathrm{Cr}$ composition fluctuations also increases with time $(\Delta c \approx 0.36$ and 0.32 after 598 hours, increasing to $\Delta c \approx 0.58$ and 0.55 after 2900 hours, employing the $P_{a}$ and square wave models respectively). The estimated wavelengths and amplitudes of decomposition are significantly greater in as-received material than in recrystallised material for a given ageing treatment. Contingency tables [24] did not suggest significant partitioning of $\mathrm{Al}$ from the $\mathrm{Cr}$-rich phase after ageing for 598 hours, when compared to homogenised material [15]. Partitioning of $\mathrm{Al}$ was evident for material aged for 2900 hours [25].

The composition depth profiles for recrystallised material aged for 2900 hours (Figure 1) additionally reveal the presence of $\mathrm{Ti}$ - and Si-enriched particles, the measured compositions of which are shown in Table 3. Similar particles were found in as-received material aged for 2900 hours. No such particles were detected after 598 hours ageing in either recrystallised nor as-received material. The precipitates are apparently located at the interface between the Fe-rich $\alpha$ and $\mathrm{Cr}$-rich $\alpha$ ' phases.

Table 3: Measured compositions of Ti-rich phases in homogenised MA 956 aged for 2900 hours at $475^{\circ} \mathrm{C}$. It is expected that simultaneous sampling of the decomposed matrix and the small Ti-rich precipitates will dilute their compositions.

\begin{tabular}{|c|c|c|c|c|}
\cline { 2 - 5 } \multicolumn{1}{c|}{} & Precipitate 1 & Precipitate 2 & Precipitate 3 & Precipitate 4 \\
\hline $\mathrm{Fe}$ & $51.1 \pm 2.25$ & $52.1 \pm 2.35$ & $43.7 \pm 1.95$ & $55.9 \pm 2.92$ \\
$\mathrm{Cr}$ & $27.6 \pm 2.01$ & $31.3 \pm 2.18$ & $29.4 \pm 1.79$ & $7.9 \pm 1.59$ \\
$\mathrm{Al}$ & $9.13 \pm 1.29$ & $5.96 \pm 1.11$ & $11.7 \pm 1.26$ & $16.6 \pm 2.18$ \\
$\mathrm{Ti}$ & $6.69 \pm 1.13$ & $5.96 \pm 1.11$ & $7.1 \pm 1.01$ & $8.6 \pm 1.65$ \\
$\mathrm{Si}$ & $5.50 \pm 1.02$ & $4.64 \pm 0.99$ & $8.2 \pm 1.15$ & $11.0 \pm 1.84$ \\
\hline
\end{tabular}

\subsection{PoSAP analysis}

Figure 2 shows PoSAP atom distributions for $\mathrm{Cr}, \mathrm{Al}$ and Ti in recrystallised MA 956 aged for 2900 hours at $475{ }^{\circ} \mathrm{C}$. While decomposition of the matrix is evident from the $\mathrm{Cr}$ atom distribution, little partitioning of $\mathrm{Al}$ to the Fe-rich $\alpha$ phase is evident. Ti-rich precipitates are located at $\alpha / \alpha^{\prime}$ interfaces: ompositional analysis of the precipitates yields $11.6 \pm 1.4 \mathrm{Ti}-23.3 \pm 1.8 \mathrm{Al}-17.7 \pm 1.6 \mathrm{Cr}-47.4 \pm 2.1 \mathrm{Fe}$ (at.\%). PoSAP data suggests a higher Ti content than that obtained by APFIM analysis - note that the higher Al content may include a contribution due to Si which may not be resolved from the mass spectra. The precipitate number density may be estimated as $1 \pm 0.3 \times 10^{24} \mathrm{~m}^{-3}$. 


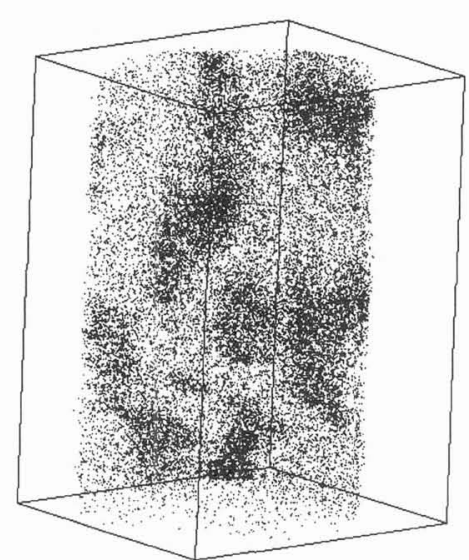

Cr

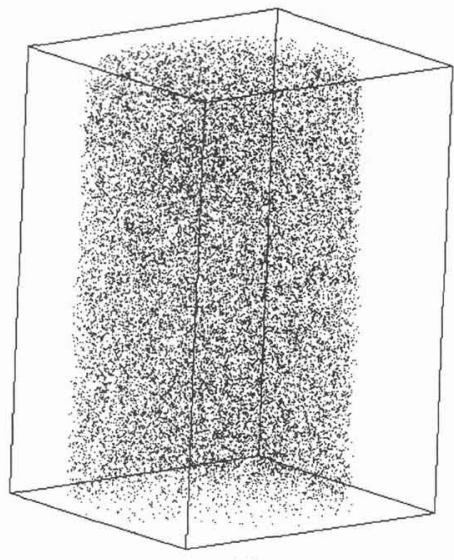

Al

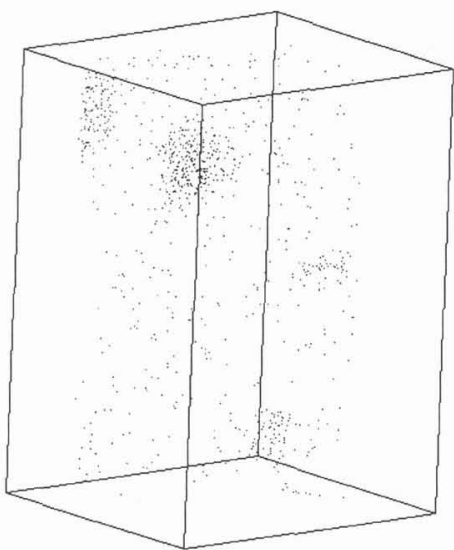

$\mathbf{T i}$

Figure 2: PoSAP atom distributions for solute species (Cr, Al, Ti) in recrystallised MA 956 aged for 2900 hours at $475^{\circ} \mathrm{C}$. Each dot corresponds to the identification and positioning of a single ion. Analysed volume $\approx 14 \mathrm{~nm}$ diameter $\times 20 \mathrm{~nm}$ depth.

\section{DISCUSSION}

APFIM analysis of phase-separated MA 956 revealed insignificant partitioning of Al after ageing recrystallised material for 598 hours at $475^{\circ} \mathrm{C}$. Ageing to 2900 hours was accompanied by partitioning of Al to the Fe-rich $\alpha$ phase. Figure 3 shows the chemical potential $\mu_{A l}^{\alpha^{\prime}}$ of $\mathrm{Al}$ in the $\mathrm{Cr}$-rich $\alpha^{\prime}$ phase as a function of $\mathrm{Cr}$ partitioning only, employing thermodynamic data from the SGTE solution database [19]. It is seen that $\mu_{A l}^{\alpha^{\prime}}$ increases more rapidly when $\Delta c \geq 0.25$, consistent with the observation of insignificant partitioning of $\mathrm{Al}$ after ageing at $475^{\circ} \mathrm{C}$ for 598 hours when $\Delta c \approx 0.25$. Thus, it appears that the partitioning of $\mathrm{Al}$ commences when there exists a sufficient driving force i.e. at later stages of phaseseparation when the chemical potential of $\mathrm{Al}$ in the two phases is sufficiently different. This contrasts with the behaviours of $\mathrm{Co}$ and $\mathrm{Ni}$ : Co was observed to have partitioned at all stages of decomposition in $\mathrm{Fe}-\mathrm{Cr}$ Co alloys $[4,6]$ while $\mathrm{Ni}$ was observed to have partitioned significantly in $\mathrm{Fe}-45 \mathrm{Cr}-5 \mathrm{Ni}$ (at.\%) after ageing for 500 hours at $500^{\circ} \mathrm{C}$ [13], presumably since their driving forces for partitioning are sufficiently high at these stages of decomposition.

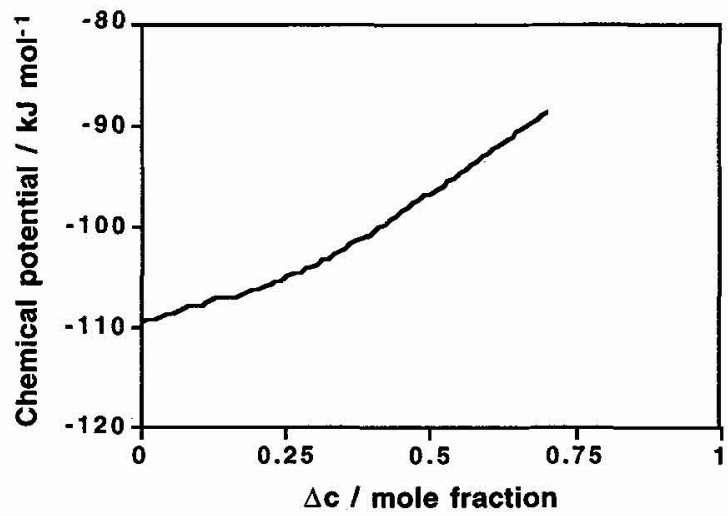

Figure 3: Chemical potential $\mu_{A l}^{\alpha}$ of $\mathrm{Al}$ in the $\mathrm{Cr}$-rich $\alpha^{\prime}$ phase as a function of the amplitude $\Delta c$ of $\mathrm{Cr}$ partitioning, employing thermodynamic data from the SGTE solution database in ThermoCalc (19). 
The wavelength and amplitude of decomposition were found to be significantly larger in aged as-received material compared to aged homogenised material, consistent with coarsening accelerated by the enhanced solute mobilities associated with the highly-dislocated as-received material.

The Ti- and Si-rich precipitates apparently form in a similar manner to G-phase precipitates (model based on $\mathrm{Ni}_{16} \mathrm{Si}_{7} \mathrm{Ti}_{6}$ and in which $\mathrm{Cr}, \mathrm{Fe}, \mathrm{Mo}, \mathrm{Mn}, \mathrm{V}, \mathrm{Nb}$, Ta, Hf and $\mathrm{Zr}$ may substitute for $\mathrm{Ti}$ and $\mathrm{Ni}$ ) found during ageing of supersaturated $\mathrm{Fe}-\mathrm{Cr}$ based ferrites [5, 8, 26-28]. Note that MA 956, however, is a $\mathrm{Ni}$-free alloy. G-phase precipitates form at the $\alpha / \alpha^{\prime}$ interfaces at later stages of decomposition. Further analysis of the precipitates in MA 956 is on-going.

\section{CONCLUSIONS}

Phase separation during ageing of MA 956 at $475{ }^{\circ} \mathrm{C}$ resulted in the formation of Fe-rich $\alpha$ and $\mathrm{Cr}$-rich $\alpha^{\prime}$ domains. Insignificant partitioning of $\mathrm{Al}$ to the Fe-rich phase was observed after ageing for 598 hours, contrary to thermodynamic predictions. Ageing for 2900 hours resulted in coarsening of the microstructure, increased amplitude of decomposition and Al partitioning. Thermodynamic data showed that the chemical potential of $\mathrm{Al}$ in the $\mathrm{Cr}$-rich $\alpha^{\prime}$ phase increased more rapidly for later stages of phase separation: $\mathrm{Al}$ only partitions when a sufficient driving force arises as a result of phase decomposition of $\mathrm{Cr}$ in $\mathrm{Fe}$. The partitioning behaviour of $\mathrm{Al}$ contrasts with those of $\mathrm{Co}$ and $\mathrm{Ni}$ in $\mathrm{Fe}-\mathrm{Cr}$ based alloys. The wavelength and amplitude of decomposition were found to be significantly larger in aged as-received material compared to aged homogenised material. Ti- and Si-rich precipitates were found at the $\alpha / \alpha^{3}$ interfaces at later stages of ageing.

\section{REFERENCES}

[1] Brenner S.S., Miller M.K. and Soffa W.A., Scripta Metall. 16 (1982) 831-836.

[2] Zhu F., Wendt H. and Haasen P., Scripta Metall. 16 (1982) 1175-1180.

[3] Brenner S.S., Camus P.P., Miller M.K. and Soffa W.A., Acta Metall. 32 (1984) 1217-1227.

[4] Zhu F., Haasen P. and Wagner R. Acta Metall. 34 (1986) 457-463.

[5] Miller M.K. and Bentley J., Mater. Sci. Tech. 6 (1990) 285-292.

[6] Miller M.K., Camus P.P. and Hetherington M.G., Mat. Res. Soc. Symp. Proc. 232 (1991) 59-64.

[7] Brown J.E. and Smith G.D.W., Surf. Sci. 246 (1991) 285-291.

[8] Danoix F., Auger P. and Blavette D., Surf. Sci. 266 (1992) 364-369.

[9] Ishikawa Y. and Yoshimura T., Mater. Trans. JIM 35 (1994) 895-901.

[10] Miller M.K., Hyde J.M., Cerezo A. and Smith G.D.W., App. Surf. Sci. 87/88 (1995) 323-328.

[11] Miller M.K., Hyde J.M., Hetherington M.G., Cerezo A. and Smith G.D.W. and Elliot C.M., Acta Metall. Mater. 43 (1995) 3385-3402.

[12] Ishikawa Y., Yoshimura T., Moriai A., Kuwano H., Mater. Trans. J.I.M. 36 (1995) 16-22.

[13] Miller M.K., Anderson I.M., Bentley J. and Russel K.F., Appl. Surf. Sci. 94/95 (1996) 391-397.

[14] Miller M.K. and Russell K.F., Appl. Surf. Sci. 94/95 (1996) 398-402.

[15] Read H.G. and Murakami H., Appl. Surf. Sci. $94 / 95$ (1996) 334-342.

[16] Ubhi H.S., Hughes T.A. and Nutting J., in Proc. Conf. Frontiers of High Temperature Materials (1981) 33-38.

[17] Waugh A.R., Richardson C.H. and Jenkins R., Surf. Sci., 266 (1992) 501-505.

[18] Cerezo A., Godfrey T.J., Grovenor C.R.M., Hetherington M.G., Hoyle R.M., Jacubovics J.P., Liddle J.A., Smith G.D.W. and Worrall G.M., J. Microscopy, 154 (1989) 215-225.

[19] ThermoCalc, Division of Physical Metallurgy, Royal Institute of Technology, Stockholm (1992).

[20] Andersson J.O. and Sundman B., Calphad 11 (1987) 83-92.

[21] Godfrey T.J., Hetherington M.G., Sassen J.M. and Smith G.D.W., J. Physique 49(C6) (1988) 421-426.

[22] Miller M.K., Bowman K.O., Cerezo A. and Hyde J.M., Appl. Surf. Sci. 67 (1993) 429-435.

[23] Lundin L. and Richarz B., App. Surf. Sci. 87/88 (1995) 194-199.

[24] Miller M.K. and Smith G.D.W., Atom Probe Microanalysis: Principles and Applications (Materials Research Society, Pittsburgh 1989) pp. 211-213.

[25] Read H.G., Murakami H. and Hono K., submitted to Scripta Materialia.

[26] Vitek J.M., Metall. Trans. 18A (1987) 154-156.

[27] Auger P., Danoix F., Menand A., Bonnet S., Bourgoin J. and Guttmann M., Mater. Sci. Tech. 6 (1990) $301-313$.

[28] Leax T.R., Brenner S.S. and Spitznagel J.A., Metall. Trans. 23A (1992) 2725-2736. 